\title{
Symptomatic gastro-oesophageal reflux as a risk factor for oesophageal adenocarcinoma
}

Lagergren J, Bergström R, Lindgren A, Nyrén O. Symptomatic gastroesophageal reflux as a risk factor for esophageal adenocarcinoma. $N \mathrm{Engl} f \mathrm{Med}$ 1999;340:825-31.

\section{Background}

The causes of adenocarcinomas of the esophagus and gastric cardia are poorly understood. We conducted an epidemiologic investigation of the possible association between gastroesophageal reflux and these tumors.

\section{Methods}

We performed a nationwide, population-based, casecontrol study in Sweden. Case ascertainment was rapid, and all cases were classified uniformly. Information on the subjects' history of gastroesophageal reflux was collected in personal interviews. The odds ratios were calculated by logistic regression, with multivariate adjustment for potentially confounding variables.

\section{Results}

Of the patients interviewed, the 189 with esophageal adenocarcinoma and the 262 with adenocarcinoma of the cardia constituted 85 percent of the 529 patients in Sweden who were eligible for the study during the period from 1995 through 1997. For comparison, we interviewed 820 control subjects from the general population and 167 patients with esophageal squamous-cell carcinoma. Among persons with recurrent symptoms of reflux, as compared with persons without such symptoms, the odds ratios were 7.7 (95 percent confidence interval, 5.3 to 11.4 ) for esophageal adenocarcinoma and 2.0 (95 percent confidence interval, 1.4 to 2.9 ) for adenocarcinoma of the cardia. The more frequent, more severe, and longer-lasting the symptoms of reflux, the greater the risk. Among persons with long-standing and severe symptoms of reflux, the odds ratios were 43.5 (95 percent confidence interval, 18.3 to 103.5) for esophageal adenocarcinoma and 4.4 (95 percent confidence interval, 1.7 to 11.0 ) for adenocarcinoma of the cardia. The risk of esophageal squamous-cell carcinoma was not associated with reflux (odds ratio, 1.1; 95 percent confidence interval, 0.7 to 1.9 ).

\section{Conclusions}

There is a strong and probably causal relation between gastroesophageal reflux and esophageal adenocarcinoma. The relation between reflux and adenocarcinoma of the gastric cardia is relatively weak.

\section{Comment}

This study is a model of well planned and executed epidemiological research. Lagergren and colleagues conducted a case control study of risk factors for oesophageal adenocarcinoma. They obtained standardised information on personal history, endoscopy, and pathology in $85 \%$ of eligible cases of adenocarcinoma in the entire country of Sweden over three years. The strengths of the study design include using two control groups and taking steps to avoid reversed causality. The first control group comprised randomly selected age and sex matched subjects from the entire Swedish population. The second control group comprised patients with squamous oesophageal carcinoma who were not aware of their cancer type, which should exclude recall bias of symptoms compared with those with adenocarcinoma. By limiting recall of reflux symptoms to at least five years before the diagnosis of cancer, the chance that the tumour caused these symptoms was excluded.

Lagergren et al found that reflux had a strong association with oesophageal adenocarcinoma, a weak association with adenocarcinoma of the cardia, and no association with squamous carcinoma. The results are consistent with an earlier case control study using different methodology (review of past medical records) ${ }^{1}$ which also found that reflux disease was associated with adenocarcinoma. The authors found no indication that treatment of reflux reduced the risk of oesophageal cancer.

The authors noted reflux symptoms equally often in adenocarcinoma cases with or without Barrett's oesophagus. They questioned the role of Barrett's oesophagus in the carcinogenic pathway. However, $62 \%$ of their oesophageal adenocarcinomas had Barrett's oesophagus, which we would expect in $<1 \%$ of asymptomatic individuals and in $3-7 \%$ of patients with reflux symptoms and no cancer. ${ }^{2}$ There is a large body of evidence showing an increased risk of cancer in Barrett's oesophagus. ${ }^{2}$ We continue to believe that Barrett's oesophagus is the precursor lesion for most cases of oesophageal adenocarcinoma although the enlarging tumour may conceal the underlying area of intestinal metaplasia in which it originated.

The paper by Lagergren et al aroused much interest in the USA. It was reviewed in national and local newspapers, which reported that subjects with reflux had an $\sim 8-43$ times increased cancer risk, causing alarm in some quarters and extra referrals to gastroenterologists. We would rather emphasise the low risk of cancer in the individual patient with reflux. Some $15-20 \%$ of adults have reflux symptoms every week, ${ }^{3}$ as did $16 \%$ of controls in the Lagergren report. A population of 100000 would include over 10000 subjects with reflux symptoms but the incidence of oesophageal adenocarcinoma is only about 2.3/100 000 per year. ${ }^{45}$ Although the risk may be greater in males over 50 with a long history, clearly most heartburn sufferers never develop oesophageal cancer. We often perform endoscopy in patients and even colleagues with reflux symptoms for reassurance but do not recommend endoscopic screening of the general reflux population. For patients with known Barrett's oesophagus, endoscopic surveillance for early detection of cancer or dysplasia is probably beneficial. ${ }^{6}$

A J CAMERON 
Y ROMERO

Mayo Clinic, W19, 200 First Street SW, Rochester, Minnesota 55905, USA

Correspondence to: Dr AJ Cameron. Email: cameron.alan@mayo.edu

Potential conflict of interest: Dr A J Cameron is currently collaborating with Dr A J Lagergren.

1 Chow WC, Finkle WD, McLaughlin JK, et al. The relation of gastroesophageal reflux disease and its treatment to adenocarcinomas of the esophagus and gastric cardia. $\mathcal{F A M A} 1995 ; 274: 474-7$.
2 Cameron AJ. Epidemiology of columnar-lined esophagus and adenocarcinoma. Gastroenterol Clin N Am 1997;26:487-94.

3 Locke GR III, Talley NJ, Fett SR, et al. Prevalence and clinical spectrum of gastroesophageal reflux: a population based study in Olmsted County, Minnesota. Gastroenterology 1997;112:1448-56.

4 Bytzer P, Christensen PB, Damkier P, et al. Adenocarcinoma of the esophagus and Barrett's esophagus: a population-based study. Am f Gastroenterol 1999;94:86-91.

5 Conio M, Cameron AJ, Romero Y, et al. Barrett's esophagus and adenocarcinoma. Prevalence and incidence in Olmsted County, Minnesota. Gastroenterology 1999;116:A384.

6 Provenzale D, Schmitt C, Wong JB. Barrett's esophagus: a new look at surveillance based on emerging estimates of cancer risk. Am f Gastroenterol 1999;94:2043-53. 